\title{
Anti-tumor effect of estrogen-related receptor alpha knockdown on uterine endometrial cancer
}

\author{
Hiroshi Matsushimaㄹ, Taisuke Mori ${ }^{1}$, Fumitake Ito ${ }^{1}$, Takuro Yamamoto ${ }^{1}$, Makoto \\ Akiyama $^{1}$, Tetsuya Kokabu ${ }^{1}$, Kaori Yoriki ${ }^{1}$, Shiori Umemura ${ }^{1}$, Kyoko Akashi ${ }^{1}$ and \\ Jo Kitawaki ${ }^{1}$ \\ ${ }^{1}$ Department of Obstetrics and Gynecology, Kyoto Prefectural University of Medicine, Graduate School of Medical Science, \\ Kajii-cho, Kamigyo-ku, Kyoto, Japan
}

Correspondence to: Taisuke Mori, email: moriman@koto.kpu-m.ac.jp

Keywords: apoptosis, cell cycle arrest, ERRa, VEGF, uterine endometrial cancer

Received: December 24, $2015 \quad$ Accepted: April 16, 2016

Published: May 03, 2016

\section{ABSTRACT}

Estrogen-related receptor (ERR)a presents structural similarities with estrogen receptor (ER)a. However, it is an orphan receptor not binding to naturally occurring estrogens. This study was designed to investigate the role of ERRa in endometrial cancer progression. Immunohistochemistry analysis on $\mathbf{5 0}$ specimens from patients with endometrial cancer showed that ERRa was expressed in all examined tissues and the elevated expression levels of ERRa were associated with advanced clinical stages and serous histological type ( $p<0.01$ for each). ERRa knockdown with siRNA suppressed angiogenesis via VEGF and cell proliferation in vitro $(p<0.01)$. Cell cycle and apoptosis assays using flow cytometry and western blot revealed that ERRa knockdown induced cell cycle arrest during the mitotic phase followed by apoptosis initiated by caspase-3. Additionally, ERRa knockdown sensitized cells to paclitaxel. A significant reduction of tumor growth and angiogenesis was also observed in ERRa knockdown xenografts $(p<0.01)$. These findings indicate that ERRa may serve as a novel molecular target for the treatment of endometrial cancer.

\section{INTRODUCTION}

Endometrial cancer is the fourth most common malignancy among women [1]. In 2012, 53,630 new cases and 8,590 deaths due to endometrial cancer were reported in the United States [2]. The incidence has doubled in the last decade, especially in Japan. Most cases diagnosed at an early stage and lower histological grade can be cured. However, the prognosis of patients with higher histological grade and invasion beyond the uterus is poor [3]. Other therapeutic modalities such as chemotherapy and radiation therapy are not well-established since the tumor is less sensitive to these [4]. To date, despite the recent advances in molecular targeted therapy, only few effective therapies are available. Therefore, novel treatment strategies for endometrial cancer are desired.

The main characteristic of uterine endometrial cancer is that it is hormone dependent [5]. Estrogen is known to be associated with carcinogenesis and to promote the progression of endometrial cancer [6]. To inhibit the progression of breast cancer, the representative estrogen-dependent disease, an antagonist for estrogen receptor (ER) and/or inhibitors of aromatase, the enzyme involved in estrogen synthesis, have been widely used [7, 8]. However, these have not been very effective for uterine endometrial cancer, suggesting the existence of more complicated estrogen signaling pathways in this disease.

Estrogen-related receptor (ERR) $\alpha$, one of the orphan members of the nuclear receptor superfamily, is a constitutively active receptor that shares considerable structural homology with the classical ER $\alpha$ and ER $\beta$ $[9,10]$. Unlike ERs, ERR $\alpha$ does not bind to naturally occurring estrogens, but shares other biochemical activities with ERs, including binding to ERE. ERRs also bind to the half-site ERE, 5'-AGGTCA-3', known to as estrogen-related responsive element (ERRE) [1113]. ERR $\alpha$ is abundantly expressed in tissues rich in mitochondria and with high energy demands such as the 


\begin{tabular}{|c|c|}
\hline \multicolumn{2}{|c|}{ Table 1: Patient characteristics } \\
\hline Age (years) & $\mathbf{2 8 - 8 0}$ (mean: 56.1) \\
\hline Histological type & \\
Endometrioid & \\
Grade1 & $28(56.0 \%)$ \\
Grade2 & $8(16.0 \%)$ \\
Grade3 & $8(16.0 \%)$ \\
Serous and others & $6(12.0 \%)$ \\
\hline Myometrial invasion & $6(12.0 \%)$ \\
No invasion & $22(44.0 \%)$ \\
Less than half & $20(20 \%)$ \\
More than half & $2(2 \%)$ \\
Not known & \\
\hline Symph node metastasis & $44(88.0 \%)$ \\
Negative & $6(12.0 \%)$ \\
Positive & \\
\hline I & $34(68.0 \%)$ \\
II & $5(10.0 \%)$ \\
III & $4(14.0 \%)$ \\
IV & $50(100 \%)$ \\
\hline
\end{tabular}

Table 2: Distribution of ERR $\alpha-\mathrm{H}$-score

\begin{tabular}{|c|c|}
\hline H-score & Patient number (\%) \\
\hline $1-50$ & $3(6.0 \%)$ \\
$51-100$ & $12(24.0 \%)$ \\
$101-200$ & $26(52.0 \%)$ \\
$201-300$ & $9(18.0 \%)$ \\
\hline Total & $50(100 \%)$ \\
\hline
\end{tabular}

heart, brain, and kidneys and controls the cellular energy metabolism $[14,15]$. The expression of the three ERR isoforms has been identified in various types of cancer, including breast, prostate, colon, uterine endometrium, and ovarian cancer [16-20]. In particular, increased ERR $\alpha$ levels are correlated with a higher risk of recurrence and poor prognosis in breast cancer [16]. However, the expression and function of ERR $\alpha$ in endometrial cancer remains unclear.

We first hypothesized that a more complicated crosstalk exists between ER $\alpha$ and ERR $\alpha$. We previously reported that ERR $\alpha$ competed with ER $\alpha$ for ERE binding and inhibited $E R \alpha$ transcriptional activity in $E R \alpha$ positive endometrial cancer cells [19]. In this study, to elucidate the function of ERR $\alpha$ in endometrial cancer without ER $\alpha$ interference, we performed loss of function experiments using ER-negative cell lines. We demonstrated various anti-tumor effects of ERR $\alpha$ knockdown and potential of ERR $\alpha$ as a target for molecular therapy for uterine endometrial cancer.

\section{RESULTS}

\section{ERR $\alpha$ expression in uterine endometrial cancer cells and its link to prognosis}

We first performed an immunohistological analysis using tissue specimens. Patient characteristics are shown in Table 1. Of the 53 patients, specimens from 50 cases were available for the analysis. ERR $\alpha$ was expressed in all tissue specimens examined. The $\mathrm{H}$-score distribution of ERR $\alpha$ is presented in Table 2. ERR $\alpha$ expression was significantly elevated at higher clinical stages and in serous adenocarcinoma when compared with endometrioid adenocarcinoma (Figure 1A, 1B). However, there was no correlation between ERR $\alpha$ expression and the tumor histological grade and the depth of uterine myometrial invasion (Figure 1B, 1C). The expression of ER $\alpha$ was examined by immunohistochemistry, but there was no association between ER $\alpha$ and ERR $\alpha$ (data not shown). 
A

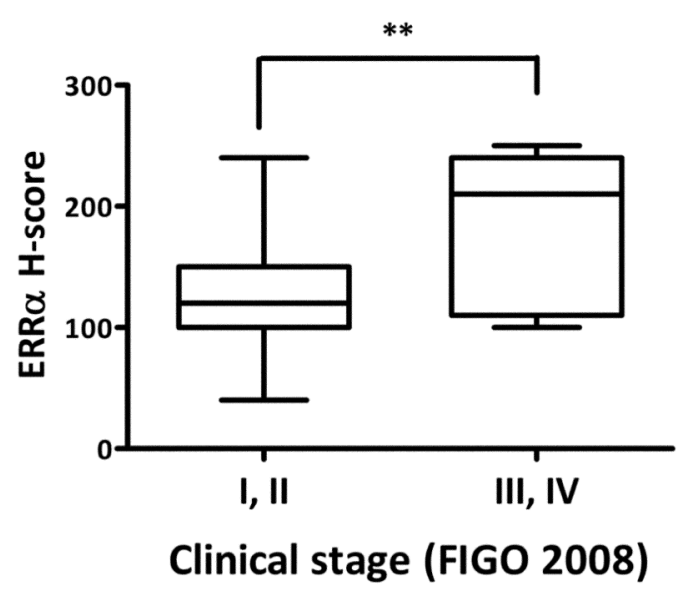

C

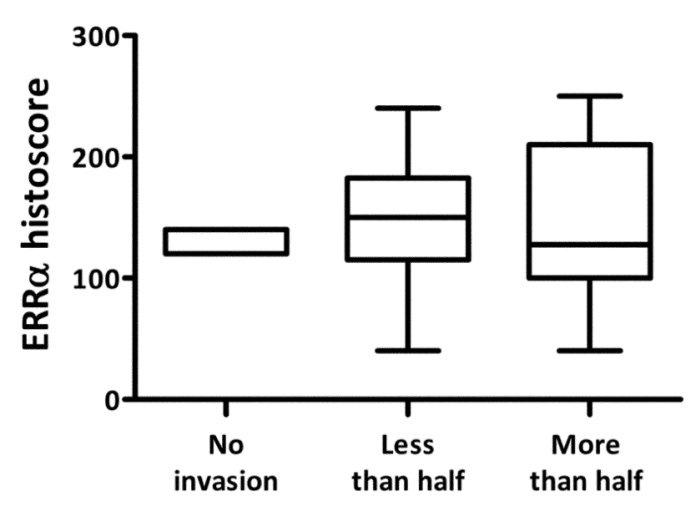

Myometrial invasion
B

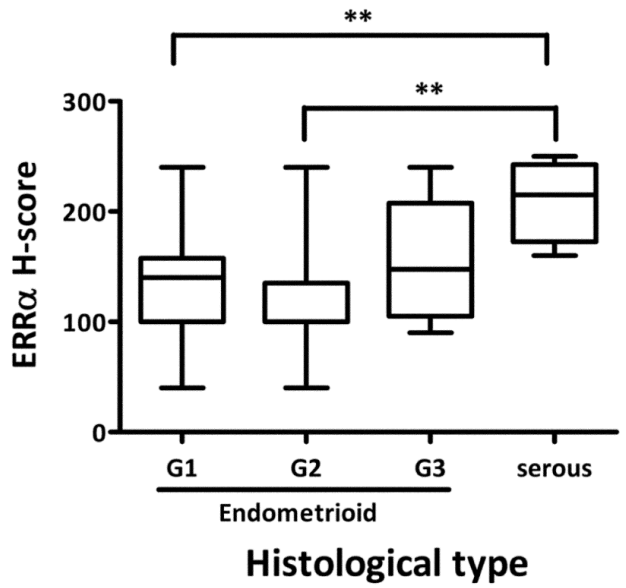

D

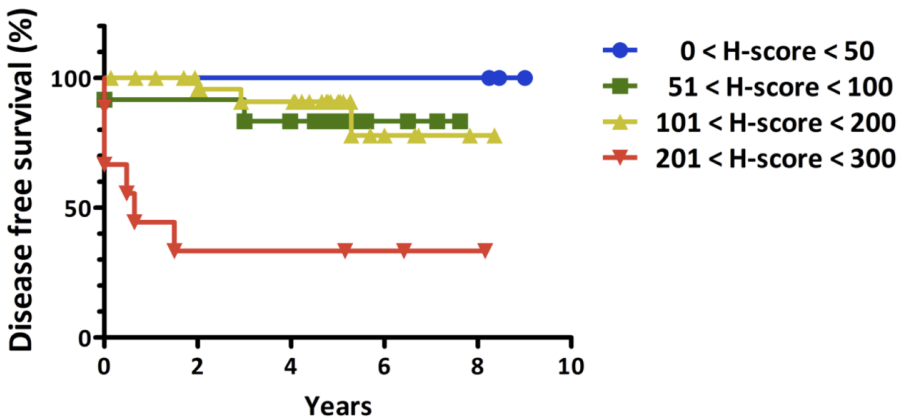

$\mathrm{E}$

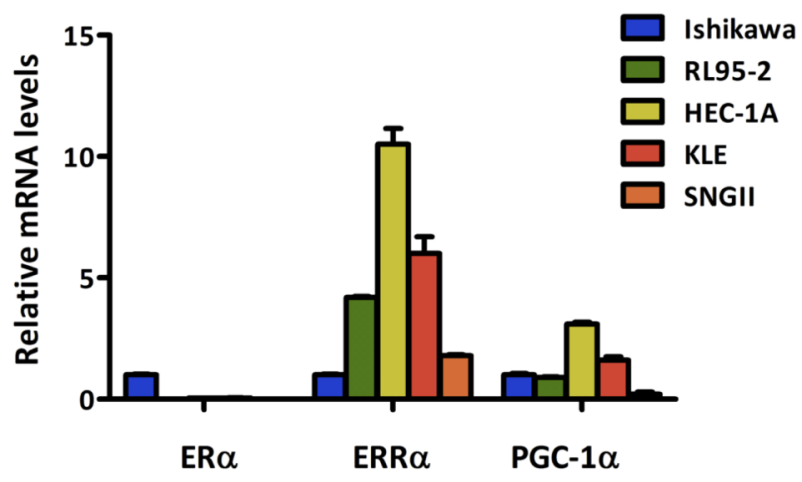

Figure 1: ERRa expression in uterine endometrial cancer in vitro and in vivo. A.-C., Association of ERR $\alpha$ expression with clinico-pathological factors. ERR $\alpha$ expression levels examined by immunohistochemistry were evaluated by H-score and their association with clinical parameters, including clinical stage based on FIGO 2008 classification A., histopathological type B., and myometrial invasion C. are presented. Statistical significance was determined by using the Kruskal-Wallis H-test. The Mann-Whitney U-test with Bonferroni correction was used as a post hoc test. D., Kaplan-Meier analysis of disease free survival in 50 patients with endometrial cancer is shown in association with ERR $\alpha$ expression $(P=0.03)$. $P$ values were based on log rank test. E., The expression of ER $\alpha, E R R \alpha$, and PGC-1 $\alpha$, known as a co-activator of ERR $\alpha$, in endometrial cancer cells was examined by real-time PCR. Significant differences are indicated as $* *$ for $P<0.01$ and * for $P<0.05$ between groups 
The Kaplan-Meier analysis indicated that the level of ERR $\alpha$ expression was inversely correlated with disease free survival (Figure 1D), suggesting that ERR $\alpha$ could be an independent prognostic factor for uterine endometrial cancer. We next performed real-time PCR to elucidate the expression levels of ER $\alpha, \mathrm{ERR} \alpha$, and PGC-1 $\alpha$, known as a robust co-activator of $\mathrm{ERR} \alpha$, in uterine endometrial cancer cell lines. All cell lines expressed ERR $\alpha$ and PGC$1 \alpha$ regardless of ER $\alpha$ expression, showing high expression in HEC-1A and KLE cells (Figure 1E).

\section{Effect of overexpression and knockdown of ERRo on angiogenesis in endometrial cancer cells}

Angiogenesis is an important factor for tumor progression. VEGF is a prominent factor for tumor angiogenesis. VEGF includes four 5'-AGGTCA-3' sites, which are known to be ERR $\alpha$ binding sites [21], in its promoter region (Figure 2A). Therefore, we performed luciferase assays using a reporter containing the $V E G F$ promoter region. Our results showed that ERR $\alpha$ transactivated VEGF. In addition, ERR $\alpha$ synergistically increased VEGF promoter activity in the presence of PGC-1 $\alpha$ in all uterine endometrial cell lines (Figure 2B). To understand the detailed molecular mechanism of ERR $\alpha$ in endometrial cancer, we next performed loss of function experiments using siRNAs. We selected HEC-1A and KLE cell lines, which are negative for $\mathrm{ER} \alpha$ and naturally express high levels of ERR $\alpha$ and PGC-1 $\alpha$ (Figure 1E). ERR $\alpha$ knockdown with siRNA in both cell lines was confirmed by real-time PCR and western blot analysis (Figure 2C). VEGF expression at the mRNA and protein levels was significantly reduced in cells knocked down for ERR $\alpha$ (Figure 2D). Additionally, HUVECs were used to assess the effects of ERR $\alpha$ knockdown on endothelial cells [22]. ERR $\alpha$ knockdown significantly suppressed HUVEC proliferation (Figure 2E). Our invasion experiments also revealed that ERR $\alpha$ knockdown significantly suppressed cell invasion and tended to decrease HUVEC migration (Figure 2F).

\section{Effect of ERRa knockdown on cell growth and its association with phases of the cell cycle and apoptosis in endometrial cancer cells}

To examine the effect of silencing ERR $\alpha$ on cell proliferation in uterine endometrial cancer cells, we performed the WST-8 assay. Silencing ERR $\alpha$ significantly inhibited the proliferation of HEC-1A and KLE cells (Figure 3A). Additionally, to investigate the effect of ERR $\alpha$ knockdown on colony formation, we performed colony formation assays. Silencing ERR $\alpha$ significantly reduced HEC-1A colony formation (Figure 3B). Flow cytometry analysis was performed to determine how
ERR $\alpha$ knockdown suppressed HEC-1A and KLE cell growth. Silencing ERR $\alpha$ caused the accumulation of cells in the G2/M- (Figure 3C, 3D) and sub-G1-phase (Figure $3 \mathrm{C}, 3 \mathrm{E})$. To further investigate the G2/M-phase arrest, we performed western blotting analysis. Silencing ERR $\alpha$ resulted in a significant increase of histone H3 Ser-10 (HH3-Ser10) phosphorylation, a representative marker of the mitotic phase, whereas the level of CDC2 and cyclin $\mathrm{B} 1$, involved in the $\mathrm{G} 2 / \mathrm{M}$ checkpoint, did not change significantly over the same time. This result suggested that the accumulation of cells in the G2/M-phase was responsible for the mitotic arrest (Figure 3F). Additionally, our western blotting analysis showed that silencing ERR $\alpha$ increased the expression of cleaved caspase-3, indicating the initiation of apoptosis. Time course experiment using flow cytometry analysis was performed to clarify the relationship between cell cycle arrest and apoptosis. The accumulation of cells at the G2/M phase was detected $24 \mathrm{~h}$ after siRNA transfection in both HEC-1A and KLE cells followed by the recruitment of Sub-G1 cells 36-60 $\mathrm{h}$ after the transfection. Our western blot analysis also showed that the increase in $\mathrm{HH} 3-\mathrm{Ser} 10$ phosphorylation was confirmed $24 \mathrm{~h}$ after transfection in both cell lines, while the increase of cleaved caspase- 3 was detected 48 $\mathrm{h}$ after transfection (Figure 3F, 3G), which was consistent with the results obtained by flow cytometry. These results suggest that ERR $\alpha$ loss of function induced cell cycle arrest at the mitotic phase in endometrial cancer cells followed by their apoptosis.

\section{Effect of ERR $\alpha$ knockdown on the sensitization of HEC-1A cells to paclitaxel}

Paclitaxel, in combination with cisplatin, is one of the most clinically used anti-cancer drugs for patients with uterine endometrial cancer [23]. To examine the effect of silencing ERR $\alpha$ on the sensitivity to paclitaxel and cisplatin, we treated ERR $\alpha$ knocked down HEC-1A and KLE cells with dimethyl sulfoxide (DMSO) alone (control), paclitaxel, and cisplatin and performed WST-8 proliferation assays. Silencing of ERR $\alpha$ did not sensitize HEC-1A cells to cisplatin, but markedly sensitized the cells to paclitaxel in a dose-dependent manner (IC50; siNC vs. siERR $\alpha \mathrm{KD}=10.0$ vs. $6.3 \mathrm{nM}$ ) (Figure 4A, 4B). At a concentration of $1.5 \mathrm{nM}$, paclitaxel alone did not decrease the viability of HEC-1A cells. However, when ERR $\alpha$ was silenced, $1.5 \mathrm{nM}$ paclitaxel significantly inhibited the cell growth of HEC-1A cells in a timedependent manner (Figure 4C). The significant difference was not found in KLE cells, because KLE cells were too sensitive to paclitaxel resulting in death even at very low experimental concentrations (data not shown). 
A

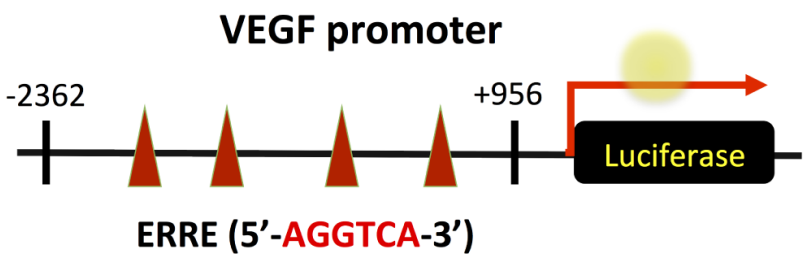

B
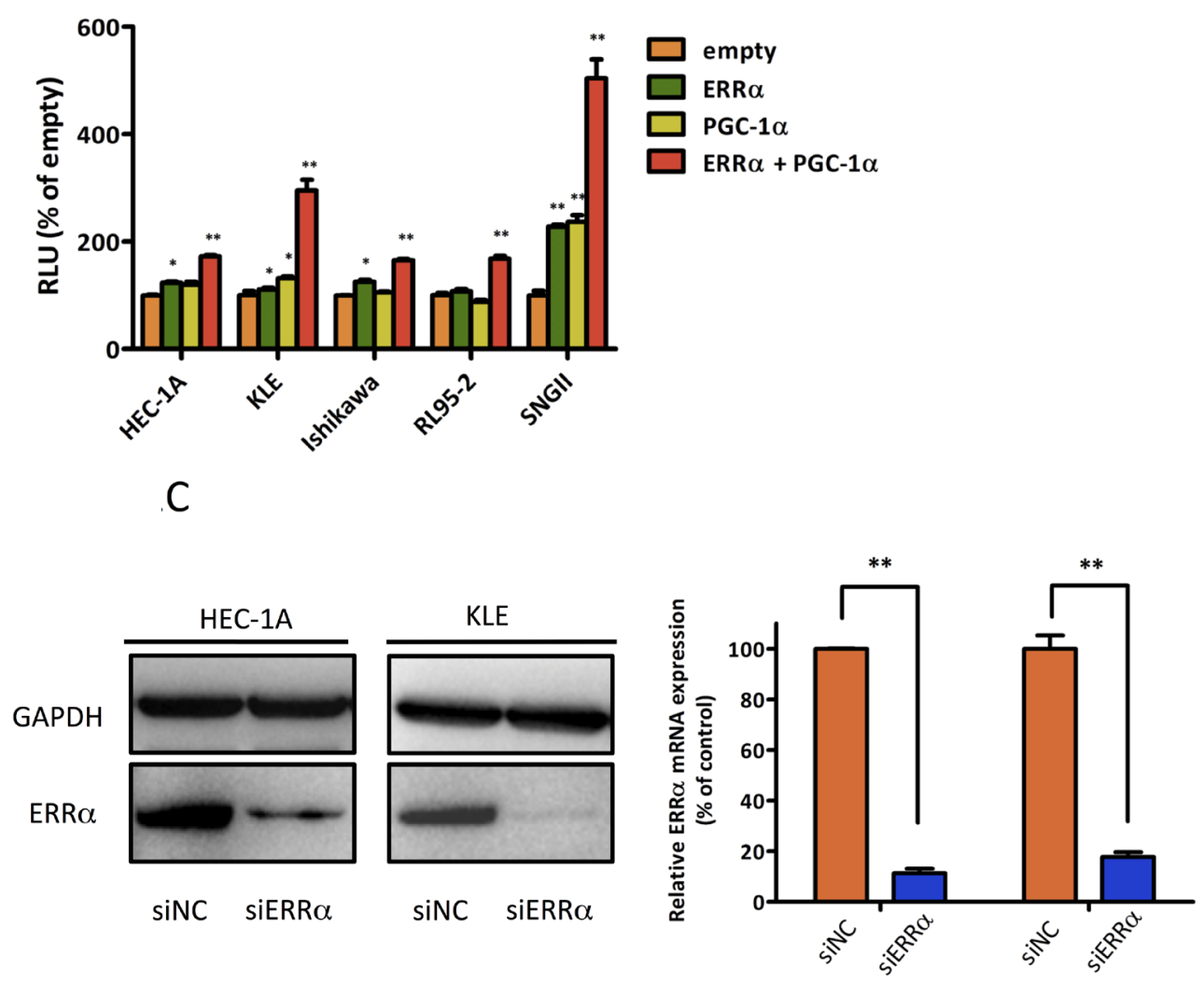

HEC-1A

KLE

\section{D}
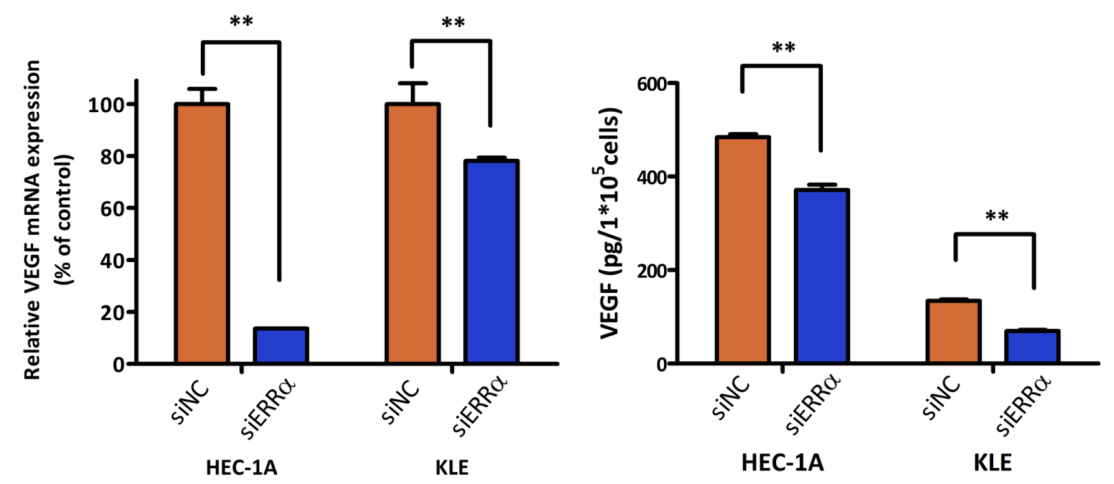


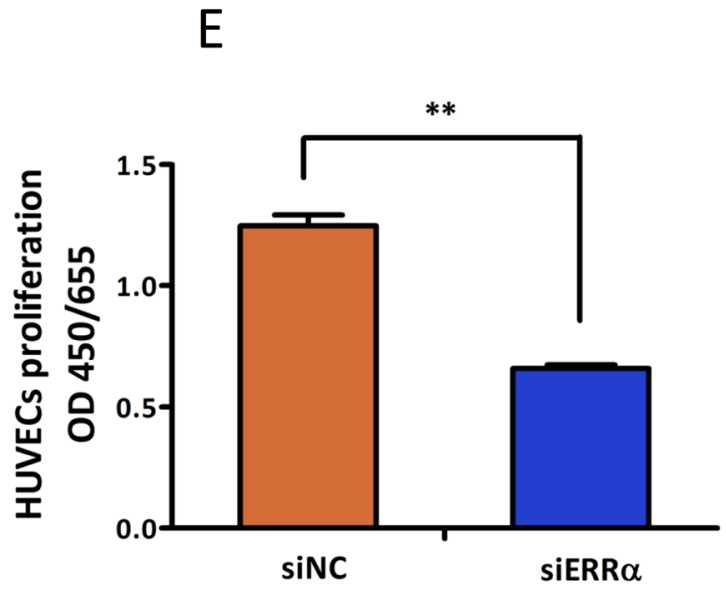

$\mathrm{F}$
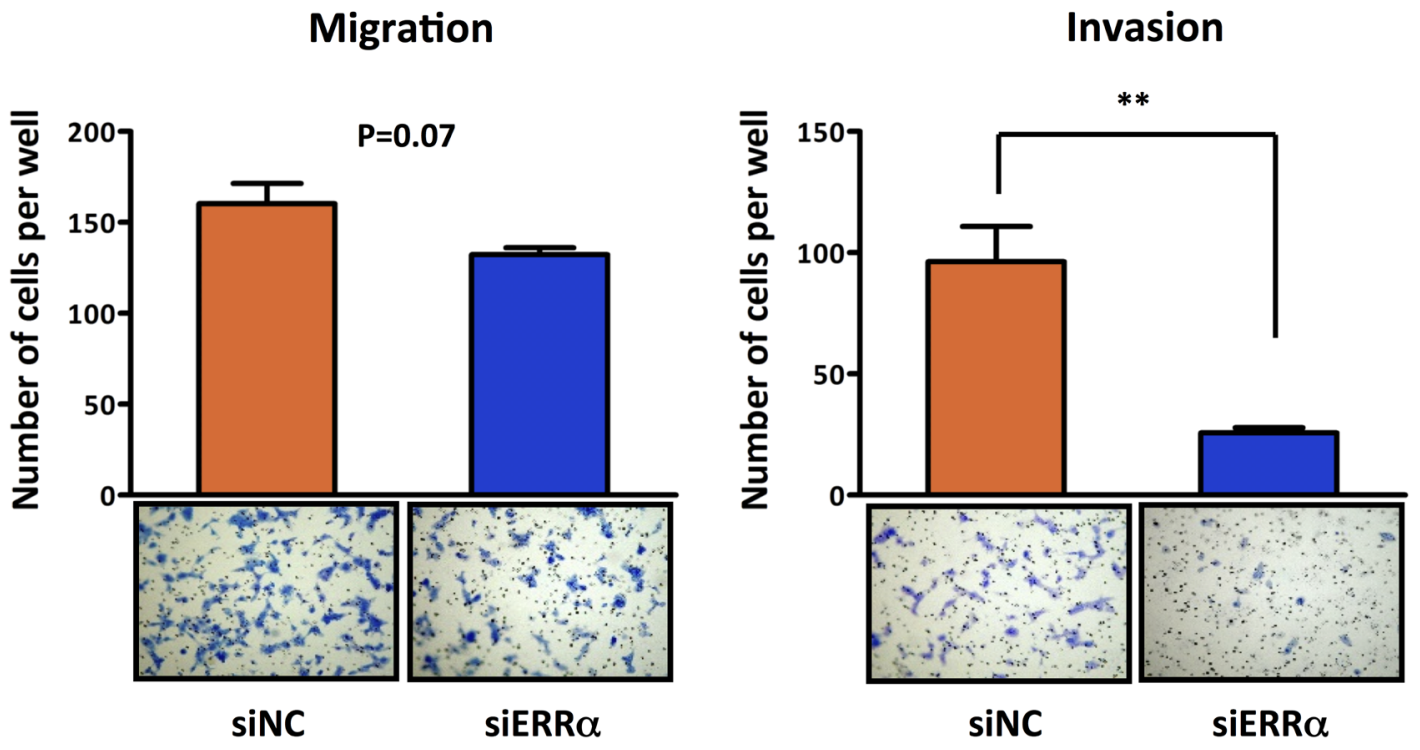

Figure 2: Effect of ERR $\alpha$ knockdown on VEGF expression and angiogenesis. A., VEGF promoter-luciferase reporter containing four copies of the ERRE site, (5'-AGGTCA-3') was transfected into endometrial cancer cell lines. B., Luciferase transcriptional activity using the VEGF promoter reporter. The pcDNA3.1-ERR $\alpha$ and PGC-1 $\alpha$ plasmids were transiently transfected into HEC-1A and KLE cells using Lipofectamine LTX. The pcDNA3.1-empty vector was used as a negative control. After transfection, the cells were incubated for 24 $\mathrm{h}$ and then lysed. The promoter activities were assessed by dual 2 2luciferase assay. Data represent means $\pm \operatorname{SEM}(n=3)$. C., The effect of ERR $\alpha$ knockdown was evaluated by real-time PCR and western blot analysis. Data represent means \pm SEM $(n=3)$. D., VEGF expression was assessed by real-time PCR and ELISA in HEC-1A and KLE cells transfected with the negative control (siNC) and ERR $\alpha$ (siERR $\alpha$ ). After the transfection, the cells were incubated for $48 \mathrm{~h}$ and then lysed for real-time PCR and incubated for $72 \mathrm{~h}$ for ELISA. Data represent means \pm SEM (real-time PCR; $n=3$, ELISA; $n=4$ ). E., HUVEC proliferation assay was performed to evaluate the angiogenic potential of cancer cells. HUVECs were cultured with the collected supernatants from endometrial cancer cells transfected with siRNA. After $72 \mathrm{~h}$ incubation, the proliferation of HUVECs was measured using the WST- 8 assay. Data represent means \pm SEM $(n=4)$. F., Matrigel invasion assay. HUVEC were co-cultured with cancer cells transfected with siRNA in a double-chamber system. After $6 \mathrm{~h}$ incubation, migration and invasion of HUVECs were assessed. Cells were counted in three high-power fields $(\times 200)$. Data represent means \pm SEM $(n=3)$. Significant differences are indicated as ** for $P<0.01$ and * for $P<0.05$. Statistical analyses were performed using the two-tailed Student's $\mathrm{t}$ test. Each assay was repeated at least three times. HUVEC, human umbilical vein endothelial cell; RLU, relative luciferase unit. 
A

HEC-1A
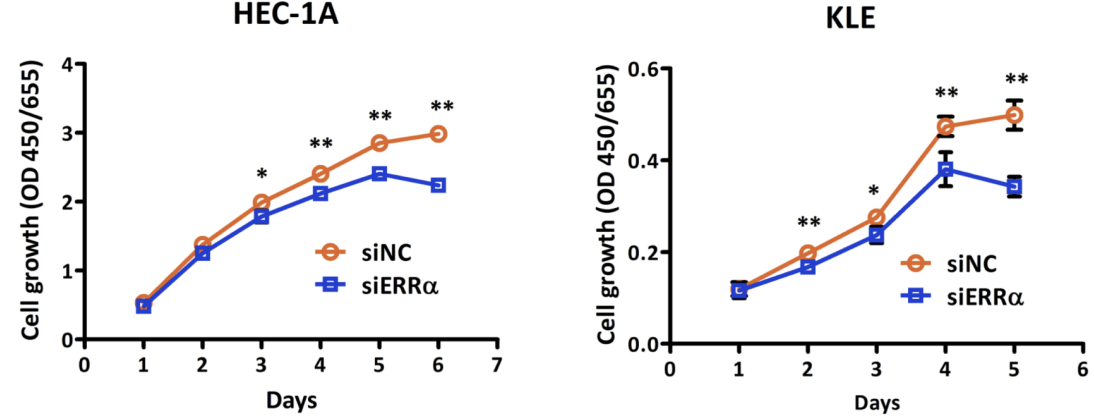

B
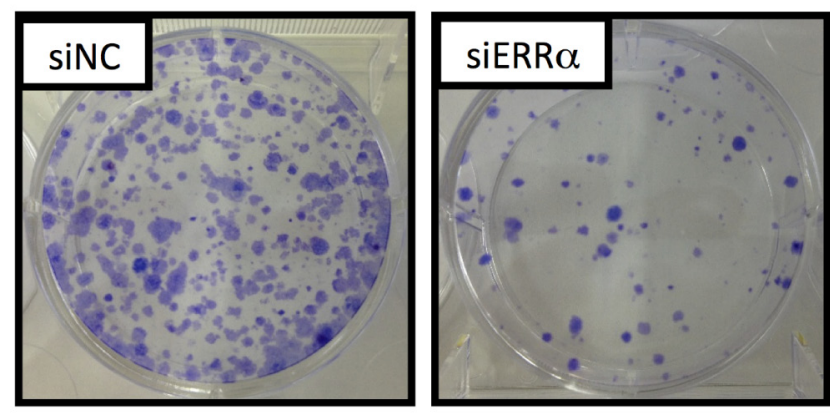

C
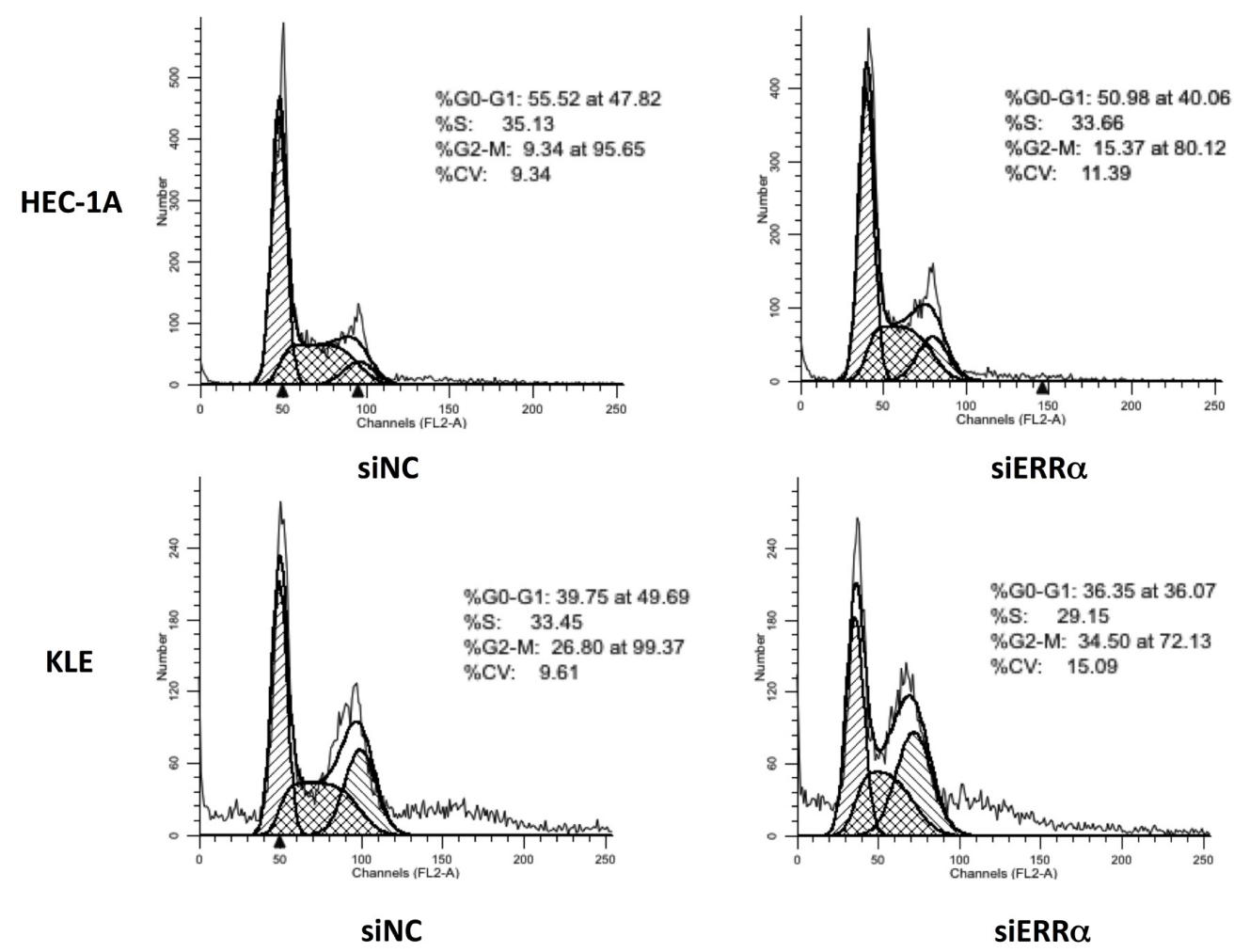

siNC SiERR $\alpha$ 


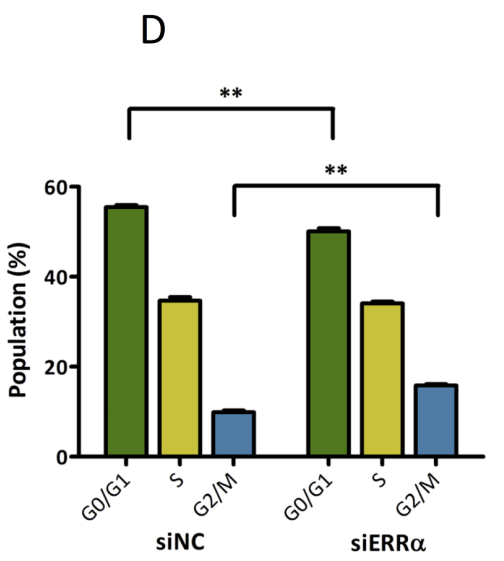

HEC-1A

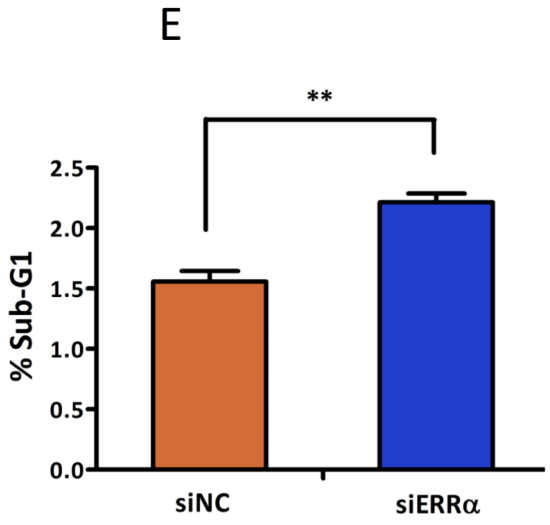

HEC-1A

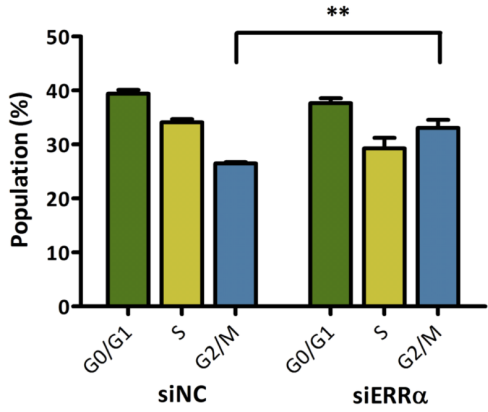

KLE
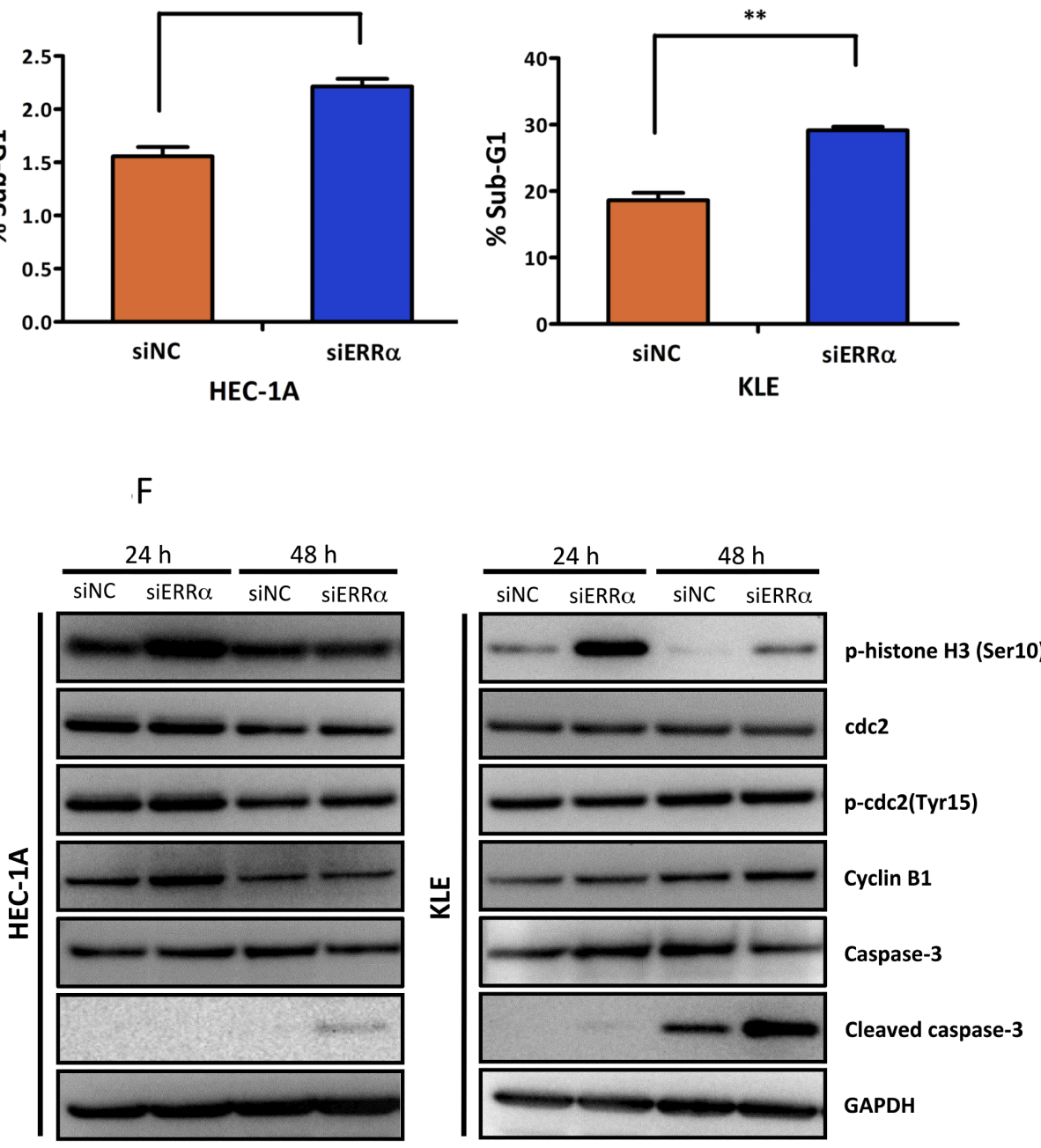
G

HEC-1A

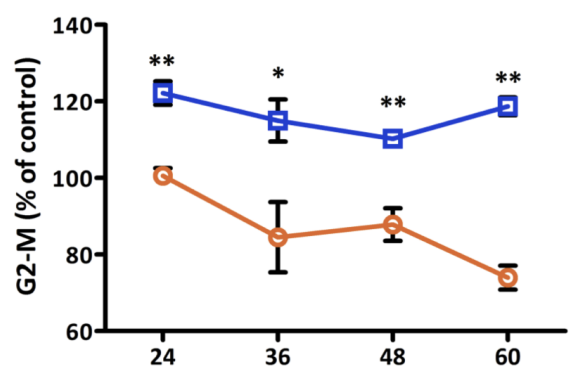

HEC-1A

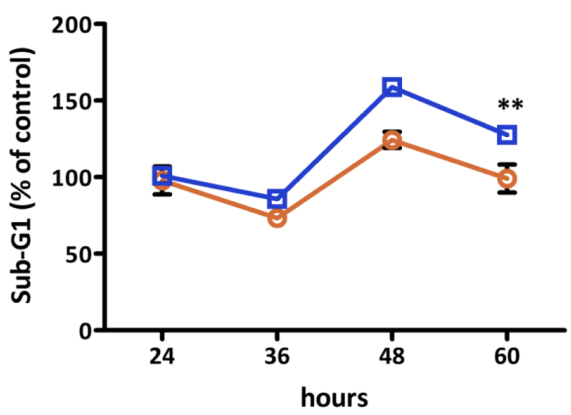

KLE
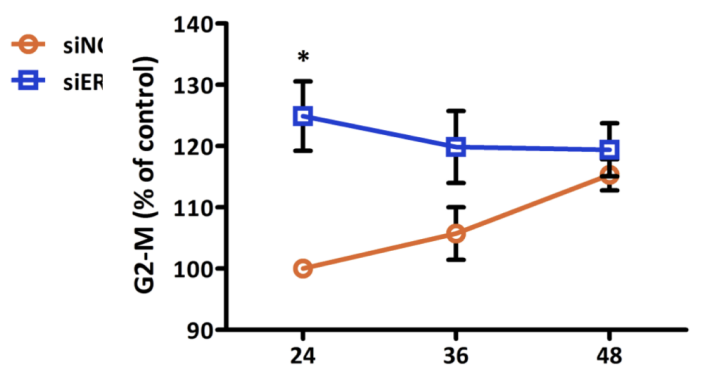

KLE
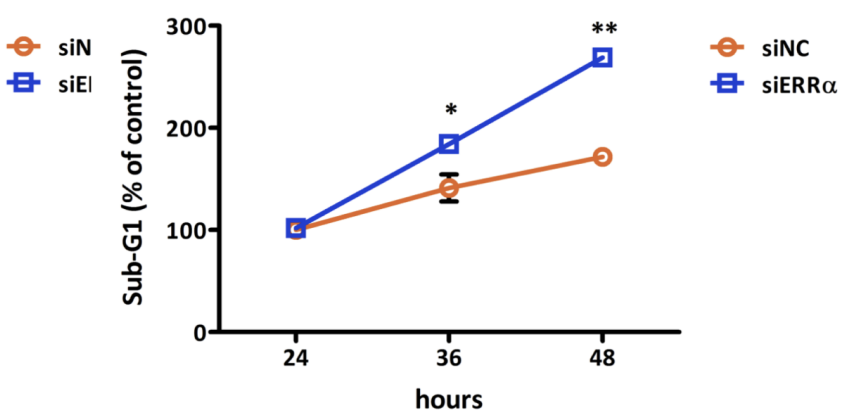

Figure 3: Effect of ERRa knockdown on the proliferation of endometrial cancer cells. A., WST-8 cell proliferation assay. After siRNA transfection, the viability of cancer cells was determined every $24 \mathrm{~h}$. Data represent means \pm SEM $(n=4)$. B., Colony formation assay. Twenty-four hours after siRNA transfection, cancer cells were reseeded at a density of 33200 cells/well in 6-well plates and cultured for 14 days. Cells were then stained with crystal violet. C., Cell cycle analysis using flow cytometry. Twenty-four to $60 \mathrm{~h}$ after siRNA transfection, cancer cells were collected and flow cytometry analysis was performed. D., Cell distribution in each phase of the cell cycle. Data represent means $\pm \operatorname{SEM}(n=3)$. E., Sub-G1 population. Data represent means $\pm \operatorname{SEM}(n=3)$. F., Western blot analysis of proteins involved in the G2/M phase and apoptosis. Twenty-four to $48 \mathrm{~h}$ after siRNA transfection, western blotting analysis for phosphohistone H3 (Ser10), CDC2, phospho-CDC2 (Tyr15), cyclin B1, and cleaved caspase-3 was performed using cell lysates. GAPDH was used as a loading control. G., Time-course analysis of the percentage of cells in G2/M and sub-G1 phases. Data represent means \pm SEM $(n=$ 3). Significant differences are indicated as ** for $P<0.01$ and $*$ for $P<0.05$. Each assay was repeated at least three times. siNC, negative control siRNA; siERR $\alpha$, ERR $\alpha$ siRNA.

\section{Effect of ERRa knockdown on tumor growth and angiogenesis in a mouse xenograft model}

To further evaluate the effect of ERR $\alpha$ knockdown on endometrial cancer cells in vivo, athymic nude mice were subcutaneously inoculated with HEC-1A cells. ERR $\alpha$ knockdown by local injection of the siRNA to the mice significantly suppressed tumor growth when compared to the control (Figure 5A, 5B). We then analyzed apoptosis in the ERR $\alpha$ knockdown tumors using TUNEL assay. Apoptosis was more frequently induced in the tumor sections from mice treated with the ERR $\alpha$ (Figure 5C). Furthermore, to assess the effect of ERR $\alpha$ knockdown on angiogenesis in vivo, we analyzed the patterns of microvessel density (MVD) using an antibody against CD31. The MVD in tumors from mice treated with the ERR $\alpha$ siRNA was significantly lower than that of tumors from control mice treated with the control siRNA (Figure 5D).

\section{DISCUSSION}

In this study, we demonstrated for the first time that silencing ERR $\alpha$ could inhibit the proliferation of uterine endometrial cancer cells in vitro and slow tumor growth in vivo in a mouse xenograft model. We also demonstrated that ERR $\alpha$ was highly expressed in the aggressive malignant phenotype and associated with unfavorable clinical outcomes for patients with uterine endometrial cancer. Furthermore, our results indicated that silencing ERR $\alpha$ could inhibit angiogenesis through VEGF and induce mitotic arrest followed by apoptosis. From these findings, we propose that ERR $\alpha$ could be a novel molecular target for the treatment of uterine endometrial cancer.

Previous studies demonstrated that ERR $\alpha$ is 
expressed in various types of cancer, including hormonedependent cancers $[16,17]$. Suzuki et al. first reported that ERR $\alpha$ is expressed in $55 \%$ of breast cancer tissues and that the expression was correlated with an increased risk of recurrence and adverse clinical outcome. Other investigators also reported ERR $\alpha$ as one of the negative prognostic factors in human prostate cancer. In this study, we re-confirmed the recent findings that the expression of $\mathrm{ERR} \alpha$ in endometrial cancer was correlated with clinicpathological parameters and showed inverse correlation with disease free survival [24, 25]. These reports also showed a significantly higher expression of ERR $\alpha$ in cancerous tissues than in the normal endometrium. Moreover, we confirmed that $\operatorname{ERR} \alpha$, with the robust co-activator PGC-1 $\alpha$, was expressed in all cell lines regardless of the ER $\alpha$ status. Although this study presents some limitations, including the small sample size, these results indicate that $\mathrm{ERR} \alpha$ may be a molecular target for the treatment of uterine endometrial cancer.

We initially focused on a major angiogenic factor, VEGF, because the promoter region of VEGF includes four ERR $\alpha$ binding sites [26]. Our luciferase promoter assay showed that ERR $\alpha$ overexpression activated the VEGF promoter reporter in all endometrial cancer cell lines. Additionally, we demonstrated that ERR $\alpha$ knockdown suppressed the expression and the function of VEGF. Angiogenesis is fundamental for tumor growth/ progression to provide nutrients and oxygen necessary for tumor cell proliferation and metastasis [27]. VEGF is a major angiogenic factor even in endometrial cancer and its expression is associated with endometrial cancer prognosis [28, 29]. Recent studies showed that ERR $\alpha$ was co-activated with PGC-1 $\alpha$ in response to hypoxia, thereby inducing VEGF expression and angiogenesis in
A

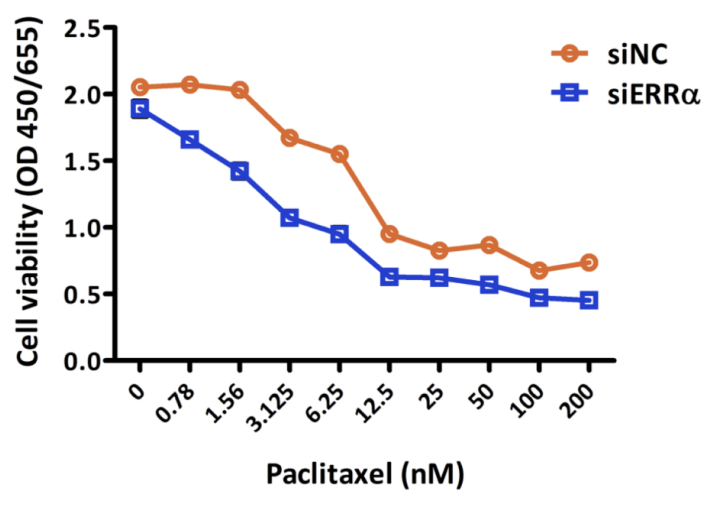

C

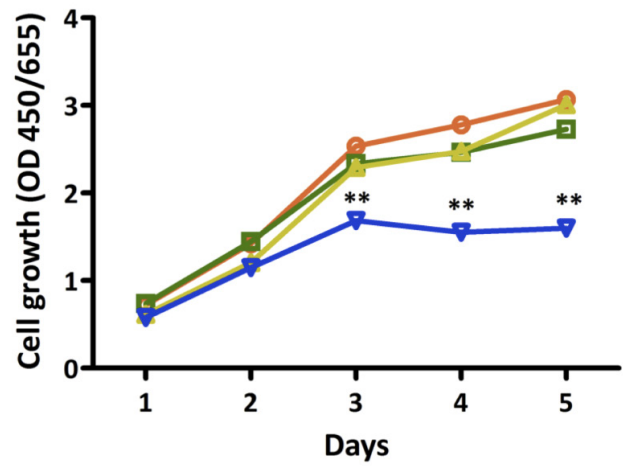

Figure 4: Effect of ERRa knockdown on the sensitivity of endometrial cancer cells to anti-cancer drugs. A. and B., Sensitivity to anti-cancer drugs using WST-8 assay. Twenty-four hours after siRNA transfection, cells were treated with DMSO alone (control), paclitaxel A., or cisplatin B. at the indicated concentrations. After 48 h, cell viability was determined using WST-8 assay. Data represent means \pm SEM $(n=4)$. C., Time course analysis of the sensitization effects with $1.5 \mathrm{nM}$ of paclitaxel. Twenty-four hours after siRNA transfection, cells were treated with DMSO alone or $1.5 \mathrm{nM}$ of paclitaxel. Cell viability was then assessed using WST- 8 assay every $24 \mathrm{~h}$. Data represent means $\pm \operatorname{SEM}(n=4) .4$ 4Significant differences are indicated as $* *$ for $P<0.01$ and $*$ for $P<0.05$. Each assay was repeated at least three times. siNC, negative control siRNA; siERR $\alpha$, ERR $\alpha$ siRNA. 


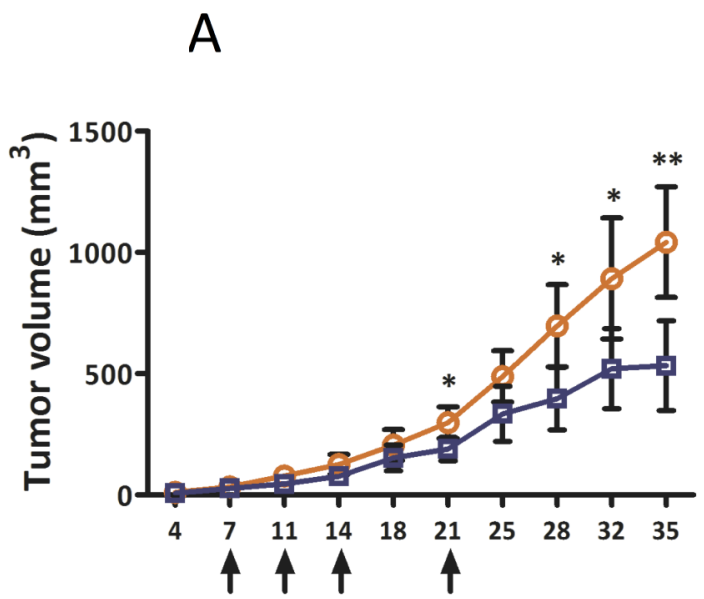

Days after tumor injection

B
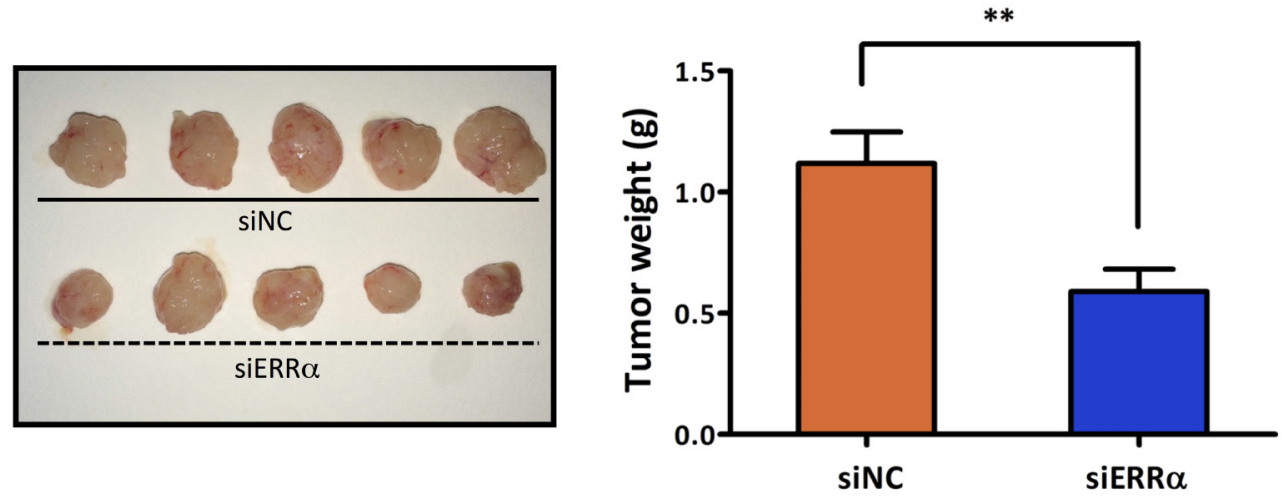

C
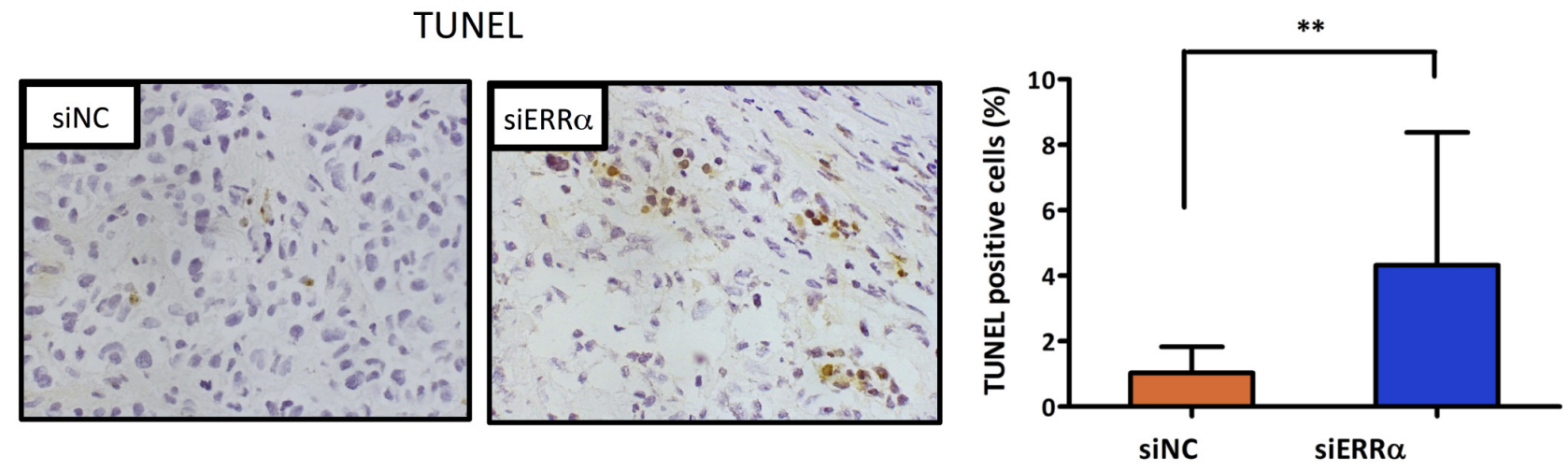
D
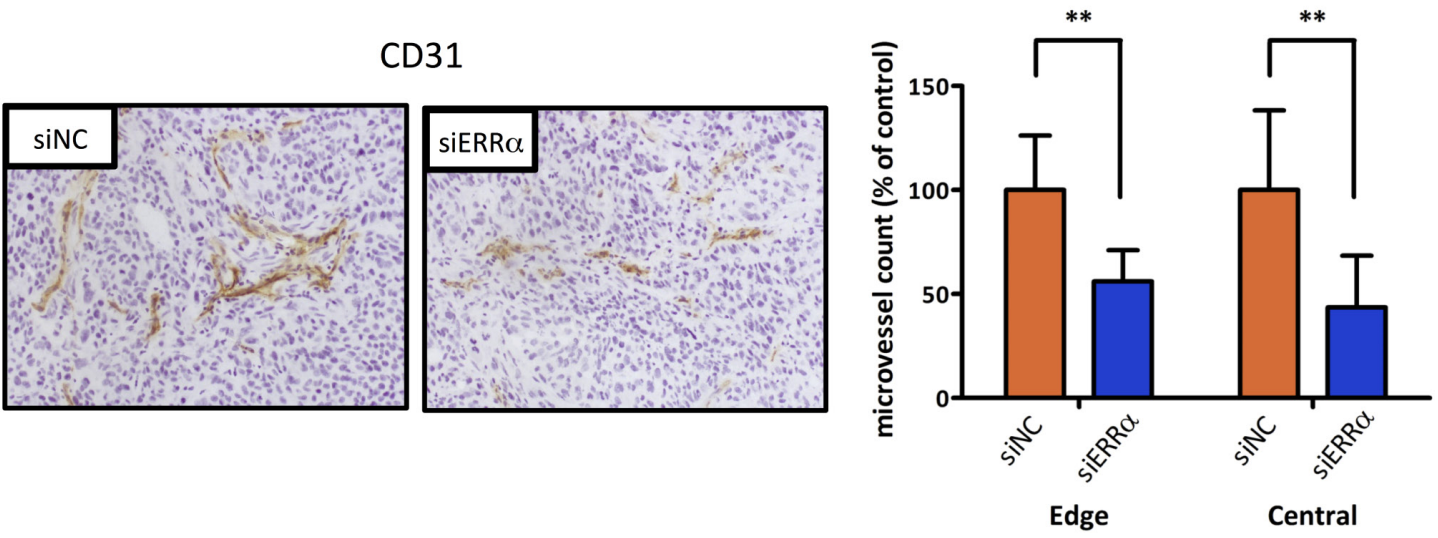

Figure 5: Effect of ERRa knockdown on proliferation and angiogenesis of endometrial cancer cells in vivo using a mouse xenograft model. A., In vivo tumor growth analysis. HEC-1 A cells $(5 \times 106$ cells per mouse $)$ were inoculated into the back of the mice by subcutaneous injection. Mice were then locally injected with 1000 pmol of either the control (blue box) or ERR $\alpha$ siRNA (orange circle) at the indicated days (arrows). The tumor volumes were measured twice a week. Data represent means $\pm \operatorname{SD}(n=5)$. B., Images and weights of excised tumors from each group. C., Apoptotic cells in the tumor sections were detected by TUNEL. The apoptotic index was defined as the percentage of immunopositive cells in 10 high-power fields $(\times 400)$. Data represent means \pm SD. D., Microvessels were labeled with an anti-CD31 antibody. Microvessels in the densestareas were selected under a low power field $(\times 40)$. CD31 immunopositive pixels per microscopic field were counted under a high-power objective $(\times 200)$ using ImageJ software. Microvessel density was defined as the percentage of CD31 immunopositive pixels per high-power field $(\times 200)$ in 10 different views, and compared in both central and edge areas of the tumor. Data represent means \pm SD. Significant differences are indicated as $* *$ for $P<0.01$ and $*$ for $P<0.05$. siNC, negative control siRNA; siERR $\alpha$, ERR $\alpha$ siRNA; TUNEL, terminal deoxynucleotidyl transferase-mediated dUTP nick end labeling.

the skeletal muscle [30]. ERR $\alpha$-dependent regulation of VEGF was reported in breast, prostate, and cervical cancer [31-33]. Our study demonstrates that the ERR $\alpha$-dependent regulation of VEGF and consequent angiogenesis are important in endometrial cancer.

We next performed loss of function experiments using siRNAs and assessed cell proliferation. Recent studies reported that ERRs are involved in cell proliferation in several cancer cells. However, little information is available on the detailed mechanisms. VEGF contributes not only to angiogenesis, but also to cancer cell proliferation via VEGF receptors (VEGF-Rs) [34]. We originally hypothesized that VEGF produced in response to ERR $\alpha$ promoted cancer cell proliferation through autocrine mechanisms. However, we confirmed that VEGF-Rs are not expressed in HEC-1A or KLE cells. Nevertheless, silencing ERR $\alpha$ inhibited cell proliferation in these cell lines. In breast cancer, Stain et al. reported that silencing ERR $\alpha$ resulted in a decrease in the growth of xenograft tumor in vivo, although it had no effect on the proliferation of estrogen-independent cells in vitro [35]. Bianco et al. demonstrated that an inverse agonist of ERR $\alpha$ reduced the proliferation of breast and prostate cancer cells by blocking the G1/S transition of the cell cycle [36]. Interestingly, our cell cycle analysis, in uterine endometrial cancer, showed that ERR $\alpha$ knockdown resulted in cell cycle arrest at the G2/M phase. Our western blot analysis showed no significant change in the expression levels of CDC-2, p-CDC2 (Tyr15), and cyclin $\mathrm{B} 1$, involved in $\mathrm{G} 2 / \mathrm{M}$ check point, while the expression of phospho-histone H3 was significantly increased, indicating the accumulation of mitotic phase cells. These results led us to conclude that the accumulation of cells in G2/M phase was not due to arrest at G2/M transition, but to the metaphase-anaphase transition, during the mitotic phase. Furthermore, our flow cytometry and western blot analysis indicated the induction of apoptosis initiated by the cleavage of caspase- 3 . Our time course experiments revealed that ERR $\alpha$ knockdown initially induced cell cycle arrest in the mitotic phase followed by apoptosis. Thus, we concluded that the cell cycle arrest at the mitotic phase was caused by ERR $\alpha$ knockdown.

We also demonstrated that silencing ERR $\alpha$ sensitized HEC-1A cells to paclitaxel, but not to cisplatin. Paclitaxel is known to deactivate cells at the mitotic phase by stabilizing microtubule and suppressing their dynamics, whereas cisplatin is not a cell cycle phase specific drug. Recent studies suggested that paclitaxel-induced apoptosis might be correlated with the phosphorylation of Bcl-2 and Bcl-xL [37, 38]. In our study, ERR $\alpha$ knockdown did not increase the phosphorylation of these proteins (Bcl2 at Ser70, Bcl-xL at Ser62). We also investigated the expression of survivin, which is considered as one of the key regulators of cell division and apoptosis [39], directly associated with polymerized tubulins and contributes to the regulation of microtubule dynamics [40]. A recent 
study indicated the up-regulation of survivin in paclitaxel resistant endometrial cancer cells when compared with parent cells [41]. However, the expression levels of survivin were not changed in our experiments (data not shown). From these experiments, we speculate that the mechanism of mitotic arrest and apoptosis by ERR $\alpha$ knockdown is different from that by paclitaxel, leading to an increase in the sensitivity to the reagent. An in depth study of the mechanism involved in this effect is warranted.

To evaluate the effect of ERR $\alpha$ knockdown on uterine endometrial cancer cells in vivo, we used a mouse xenograft model and determined that silencing ERR $\alpha$ significantly inhibited the growth of subcutaneously transplanted cancer cells. Using TUNEL assay and MVD analysis, we also demonstrated that ERR $\alpha$ knockdown induced apoptosis and suppressed angiogenesis. Taken together, these data confirm the in vitro anti-tumor effect of ERR $\alpha$ knockdown on the induction of apoptosis and the inhibition of angiogenesis.

The crosstalk between ER $\alpha$ and $E R R \alpha$ remains controversial. Studies on ERR $\alpha$ initially focused on the correlation with ER $\alpha$ because of significant similarities in their structures, particularly in the DNA binding domain. In breast cancer tissues, one group demonstrated that ERR $\alpha$ expression was not associated with ER $\alpha$ status, while others indicated that the increased level of ERR $\alpha$ was inversely correlated with ER $\alpha$ status. Additionally, the genome wide study conducted by Deblois et al. revealed that the functional overlap between ER $\alpha$ and ERR $\alpha$ was quite limited and most of their transcriptional activities were through their specific, but different binding sites in breast cancer [42]. Although the interference between $\mathrm{ER} \alpha$ and $\mathrm{ERR} \alpha$ in endometrial cancer has not yet been clarified, we previously reported that $\mathrm{ERR} \alpha$ competed with $\mathrm{ER} \alpha$ for the response element on their target genes, effecting on cell proliferation. In this study, we investigated the functional effect of ERR $\alpha$ inhibition using ER $\alpha$-independent endometrial cancer cell lines, HEC-1A and KLE cells. We also evaluated the effect of silencing ERR $\alpha$ using ER- $\alpha$-dependent Ishikawa cells. However, the suppressive effect on angiogenesis and cell proliferation was not observed (data not shown). These results indicate the existence of a complex crosstalk between ER $\alpha$ and $\mathrm{ERR} \alpha$ in endometrial cancer.

In this study, we demonstrated that ERR $\alpha$ could be a potential molecular target in ER-negative endometrial cancer cells. Further studies are warranted to strengthen our current findings and to analyze the functional crosstalk between ER $\alpha$ and ERR $\alpha$. These results can help in the development of new hormonal and molecular targeted therapy for endometrial cancer.

\section{MATERIALS AND METHODS}

\section{Reagents}

Paclitaxel was purchased from Sigma-Aldrich (St. Louis, MO, USA). Cisplatin was purchased from Wako Pure Chemicals (Osaka, JAPAN).

\section{Antibodies}

Rabbit polyclonal anti-phosphorylated-CDC2 (Tyr15) (\#9111), anti-CDC2 (\#9112), anti-cleaved caspase 3 (\#9661), anti-caspase 3 (\#9662), rabbit monoclonal antiphosphorylated-Histone H3 (ser10) (\#9706), anti-GAPDH (\#2118), mouse monoclonal anti-cyclin B1 antibodies (\#4135) were purchased from Cell Signaling Technology (Danvers, MA, USA). Mouse monoclonal anti-ERR $\alpha$ antibody (sc-65715) was purchased from Santa Cruz Biotechnology (Santa Cruz, CA, USA). Rabbit polyclonal anti-CD31 antibody (ab28364) was purchased from Abcam (Cambridge, UK). All antibodies were used at the concentration recommended by the manufacturers.

\section{Patients, specimen collection, and immunohistochemistry}

Specimens from 53 patients with uterine endometrial cancer, who underwent primary operation at the Department of Obstetrics and Gynecology, Kyoto Prefectural University of Medicine (Kyoto, Japan) between 2006 and 2010, were evaluated. These patients did not receive any chemotherapy or radiation therapy before surgery. The research protocol was approved by the Institutional Review Board and an informed consent was obtained from all patients prior to the beginning of the study. Immunohistochemical staining was performed as previously described [43]. Furthermore, the expression level of ERR $\alpha$ was assessed by H-score, a commonly used method to measure the strength of ER- and ERRstaining, which semi-quantitatively evaluates both the intensity and the percentage of cells stained at each intensity [24]. Intensities were scored as 0 (no staining), 1 (weak staining), 2 (moderate staining), 3 (strong staining) as shown in supplementary figure $\mathrm{S} 1$. The $\mathrm{H}$-score was calculated by the following algorithm: $\mathrm{H}$-score $=\Sigma(\mathrm{i}+1)$ $\times \mathrm{Pi}$ (i and Pi represent intensity and percentage of cells at each intensity). We also used the quantification method, which was appropriate for analyzing the relation of $\mathrm{H}$-score to survival rate, separating $\mathrm{H}$-score into 4 groups: $1-50,51-100,101-200$, and $>200$ [44]. 


\section{Cell lines and culture}

Human endometrial cancer cell lines, HEC-1A, KLE, and RL95-2 cell lines were purchased from the American Type Culture Collection (Manassas, VA, USA). Ishikawa and SNGII cell lines were provided by the Cell Resource Center for Biomedical Research (Institute of Development, Aging and Cancer Tohoku University, Sendai, Japan). HEC-1A cells were cultured in McCoy's 5A medium (HyClone Laboratories, South Logan, UT, USA), KLE and RL95-2 cells were maintained in Dulbecco's Modified Eagle Medium (DMEM)/ F12 (Nacalai Tesque, Kyoto, Japan), SNGII cells were cultured in Ham's F12, and Ishikawa cells were cultured in Modified Eagle Medium (MEM) (Nacalai Tesque). Each medium was supplemented with $10 \%$ fetal bovine serum (FBS) (Biowest, Nuaille, France) and penicillinstreptomycin (Nacalai Tesque). All cells were cultured at $37^{\circ} \mathrm{C}$ in a humidified $5 \% \mathrm{CO}_{2}$ atmosphere.

\section{Plasmid construction}

\section{Mammalian expression vectors}

The ERR $\alpha$ and PGC- $1 \alpha$ expression plasmids were constructed by inserting the full-length human ERR $\alpha$ and PGC-1 $\alpha$ gene (NM_004451 and NM 013261), amplified from pSG5-ERR $\alpha$ and -PGC- $1 \alpha$, kindly provided by Prof. Shiuan Chen, into the pcDNA3.1-empty plasmid (Invitrogen, Carlsbad, CA, USA) using the HindIII and XhoI sites. The pcDNA3.1-empty vector was used as a control.

\section{Reporter constructs}

Luciferase reporter plasmids, pGL3-VEGF promoter constructs containing four copies of ERRE site, (5'-AGGTCA-3'), were kindly provided by Prof. Salman Hyder (University of Missouri, Columbia, MO, USA). pGL4.74 vector (Promega, Madison, WI, USA) was used to normalize the luciferase activities.

\section{Transient transfection and luciferase reporter assay}

Twenty-four to $72 \mathrm{~h}$ after transfection using Lipofectamine LTX (Invitrogen), the luciferase reporter assay was performed with the Dual-Glo Luciferase Assay System (Promega) according to the manufacturer's protocol. Briefly, cancer cells were seeded in 24-well plates and incubated overnight. Cells were co-transfected with pGL3-VEGF promoter reporter plasmid, expression plasmid (pcDNA3.1- empty and/or - ERR $\alpha$ and/or PGC-1 $\alpha$ ), and pGL4.74 vector as transfection control. After $24 \mathrm{~h}$ of incubation, cells were lysed and assayed. The luminescence was measured with Glomax 20/20 luminometer (Promega).

\section{In vitro small interfering (si) RNA transfection}

Small interfering RNAs (siRNA) for ERR $\alpha$ ( 44829 , s4830, and s4831) and negative control siRNA (control \#1) were Silencer Select siRNAs purchased from Ambion (Austin, TX, USA), the specificity and knockdown effect of which have already been confirmed and guaranteed by the Manufacturers. The siRNA transfection experiments were performed using Lipofectamine RNAiMAX (Invitrogen) according to the manufacturer's protocol. The knockdown effects of the siRNAs were confirmed by using real-time PCR and western blotting analysis. For the following experiments, we used siRNA for ERR $\alpha$ (s4831) at a final concentration of $5 \mathrm{nM}$ because it presented the strongest knockdown activity.

\section{RNA extraction and quantitative real-time PCR}

Total RNA $(1 \mu \mathrm{g})$ was extracted from cultured cells using RNeasy Mini kit (QIAGEN, Venlo, Netherlands) and then used to synthesize cDNA with ReverTra Ace qPCR RT kit (Toyobo, Osaka, Japan). Quantitative realtime PCR was performed using CFX Connect Realtime PCR Detection System (Bio-Rad, Hercules, CA, USA) with Thunderbird SYBR qPCR Mix (Toyobo) and primers for target genes. The following primers, $E R R \alpha$ 5'-ATGGTGTGGCATCCTGTGAG-3 (forward) and 5'-TGGTGATCTCACACTCGTTGG-3' (reverse), Glyceraldehyde 3-phosphate dehydrogenase (GAPDH) 5'-GCACCGTCAAGGCTGAGAAC-3' (forward) and 5'- ATGGTGGTGAAGACGCCAGT-3' (reverse), and VEGF 5'-CGTGATGATTCTGCCCTCCT-3' (forward) and 5'-CCTTGCCTTGCTGCTCTACC-3' (reverse) were designed with primer 3 plus software and purchased from Invitrogen. The target gene mRNA level was quantified using the comparative method ( $\triangle \Delta \mathrm{CT}$ method) and normalized to $G A P D H$ expression.

\section{ELISA}

The amount of human VEGF protein was determined using a Quantikine ELISA kit (R\&D systems, Minneapolis, MN, USA) according to the manufacturer's protocol. Briefly, cells were seeded in $10 \mathrm{~cm}$ dish and RNA interference experiment was performed after $24 \mathrm{~h}$. After $72 \mathrm{~h}$, the cell culture medium was collected and centrifuged at 1,500 rpm for $5 \mathrm{~min}$ to remove any particles. The supernatants were frozen at $80^{\circ} \mathrm{C}$ until used. Human 
recombinant VEGF165 provided in the Quantikine ELISA kit was used as a standard.

\section{Cell viability assay}

Cells were seeded in 96-well plates with normal growth medium. RNA interference was performed after 24 h. Cells were cultured, treated, and cell viability was examined every day by the 2-(2-methoxy-4-nitrophenyl)3-(4-nitrophenyl)-5-(2,4-disulfophenyl)-2H-tetrazolium, a monosodium salt (WST-8) assay (Nacalai Tesque). Each experiment was performed three times using 4 replicates.

\section{HUVEC proliferation assay}

Cancer cells were seeded in $10 \mathrm{~cm}$ dish and incubated for $24 \mathrm{~h}$. Subsequently, the cells were transfected with siRNA. After $72 \mathrm{~h}$, the cultured medium was collected and centrifuged at 1,500 rpm for $5 \mathrm{~min}$ to remove any particles. The supernatants were frozen at $80^{\circ} \mathrm{C}$. Human umbilical vein endothelial cells (HUVEC) were seeded in 96-well plates. The culture medium was then replaced by the collected supernatants every $24 \mathrm{~h}$. HUVEC proliferation was assessed by using the WST-8 assay every day.

\section{HUVEC migration and invasion assay}

Migration and invasion assays were performed using uncoated and Matrigel-coated double-chamber systems (BD BioCoat ${ }^{\mathrm{TM}}$ Matrigel $^{\mathrm{TM}}$ Invasion Chamber, BD Biosciences, Bedford, MA, USA) as previously described [43]. Briefly, cancer cells were seeded into 24-well lower chamber filled with 10\% FBS contained medium and, after $24 \mathrm{~h}$, cells were transfected with siRNAs. After $72 \mathrm{~h}$ incubation, HUVEC were then seeded into upper chamber (uncoated or Matrigel-coated inserts) filled with 1\% FBS containing medium. After $12 \mathrm{~h}$, cells that migrated and invaded onto the lower side of the inserts were fixed and stained with Diff-Quick Kit (Sysmex, Kobe, Japan). The number of stained cells was counted in five fields using a microscope $(200 \times)$.

\section{Colony formation assay}

Cells were seeded in $6 \mathrm{~cm}$ dishes and transfected with siRNAs. After $24 \mathrm{~h}$, cells were harvested by trypsinization and reseeded at a density of 200 cells in each well of 6-well plates. Cells were then incubated for 14 days and stained with crystal violet.

\section{Flow cytometry analysis}

Cells were seeded in 6-well plates and RNA interference was performed. Cells were permeabilized with $0.1 \%$ Triton-X100 and the nuclei were then stained with propidium iodide (PI) after 24-48 h. The DNA content was measured using a FACS Caliber cytometer (BD biosciences) and analyzed with the ModFit LT (Verity Software, Topsham, ME, USA) and Cell Quest software package (BD biosciences).

\section{Western blot analysis}

Cell protein extracts were collected using Radioimmunoprecipitation (RIPA) buffer (Nacalai Tesque) and then mixed with SDS sample buffer $(62.5$ $\mathrm{mM}$ Tris-HCL pH 6.8, 10\% glycerol, 1\% SDS, 0.1\% 2-mercaptoethanol, $1 \mathrm{mM}$ phenylmethylsulfonyl fluoride) and heated for $15 \mathrm{~min}$ at $65^{\circ} \mathrm{C}$. The lysates were loaded onto polyacrylamide gels, subjected to electrophoresis, and transferred to a polyvinylidene difluoride membrane. The blots were blocked in blocking buffer $(5 \%$ skim milk/TBS-Tween) for $30 \mathrm{~min}$ at room temperature and incubated with appropriate primary antibody in blocking buffer overnight at $4^{\circ} \mathrm{C}$. The blots were incubated with the appropriate secondary antibody in blocking buffer for $1 \mathrm{~h}$ at room temperature. The signal was detected with ChemiLumi One (Nacalai Tesque) and ChemiDoc XRS+ system (Bio-Rad).

\section{In vivo animal study}

Female BALB/c mice (5 weeks of age) were purchased from Shimizu Co., Ltd. (Kyoto, Japan). For the in vivo study, siRNAs and the in vivo transfection kit, AteloGene Local Use, were purchased from Koken (Tokyo, Japan) [45]. The sequence of ERR $\alpha$ siRNA used in vivo was the same as that of the siRNA used in vitro. HEC-1A cells $\left(5 \times 10^{6}\right.$ cells per mouse $)$ were inoculated into the back of the mice by subcutaneous injection. The tumor volume was calculated using the following formula: $1 / 2 \times($ length $) \times(\text { width })^{2}$. After the establishment of palpable tumors (approximately $50 \mathrm{~mm}^{3}$ ), mice were locally injected with 1000 pmol of either control or ERR $\alpha$ siRNAs with AteloGene Local Use (total $0.1 \mathrm{~mL}$ ) on day $7,11,14$, and 21 after tumor injection, according to the manufacturer's protocol. Mice were sequentially monitored twice a week for 5 weeks by measuring the tumor volume and body weight. On day 28 , the tumors were excised from the euthanized mice, embedded in Tissue-Tek compound (Sakura Finetek, Tokyo, Japan), and frozen in liquid nitrogen. All experiments and procedures were approved by the Institutional Care Use Committee and performed in accordance with guidelines. 


\section{In vivo analysis of micro-vessel density (MVD)}

To quantify tumor angiogenesis, MVD was quantified. First, micro-vessels were immunostained with anti-CD31 antibody as follows: Tumor frozen sections were sliced to $6-\mu \mathrm{m}$ thickness, dried for a few hours at room temperature, and fixed in $10 \%$ formalin. Sections were washed with PBS thrice and the endogenous peroxidase activity was blocked with $0.3 \%$ hydrogen peroxide in methanol for $20 \mathrm{~min}$ at room temperature. Sections were then blocked for 30 min with $2 \%$ normal swine serum (VECTOR Laboratories, Brussels, Belgium) in PBS. Incubation with primary polyclonal rabbit antiCD31 antibody (1:50) was performed at $4^{\circ} \mathrm{C}$ overnight. Slides were then incubated with a biotinylated secondary antibody (VECTOR Laboratories) (1:200) for 30 min at room temperature. Slides were incubated with VECTASTAIN Elite ABC Kit (VECTOR Laboratories). 3,3'-Diaminobenzidine (DAB) staining was performed (DAB TRIS Tablet, Muto Pure Chemicals, Tokyo, Japan) to detect CD31 and the nuclei were counterstained with Mayer's hematoxylin (Muto Pure Chemicals). MVD was then analyzed as follows: Slides were scanned under low power field $(\times 40)$ to select micro-vessels in the densest areas. CD31 immunopositive pixels per microscopic field were counted under high power objective $(\times 200)$ using Image J software (NIH, Bethesda, MD, USA). MVD was quantified as the percentage of CD31 immunopositive pixels per high-power field in 10 views.

\section{In vivo analysis of apoptosis}

Apoptotic cells in the $6 \mu \mathrm{m}$ thick frozen sections were detected by a terminal deoxynucleotidyl transferasemediated dUTP nick end labeling (TUNEL) with the DeadEnd colorimetric Apoptosis Detection System (Promega), according to the manufacturer's protocol. The apoptotic index was defined as the percentage of immunopositive cells in 10 high-power fields $(\times 400)$.

\section{Statistical analysis}

The relation of the H-score to clinico-pathologic factors (clinical stage, histological type, and myometrial invasion) was analyzed using the Kruskal-Wallis H-test and the Mann-Whitney U-test with Bonferroni correction was used as a post hoc test. Comparisons of the means and standard error of data between two groups were performed using the Student's t test. Disease-free survival was estimated according to the Kaplan-Meier method and logrank test was used to calculate the statistical significance. $P$ values $<0.05$ were considered statistically significant.

\section{ACKNOWLEDGMENTS}

The authors thank Yunhwa Lee and Ayaka Miura for technical assistance, Prof. Chen and Prof. Hyder for providing reporter vectors.

\section{CONFLICTS OF INTEREST}

The authors declare that they have no conflict of interest to disclose.

\section{GRANT SUPPORT}

This study was supported in part by Grants-in-Aid for Scientific Research (no. 23197849) from the Japan Society for the Promotion of Science (to TM).

\section{REFERENCES}

1. DeSantis CE, Lin CC, Mariotto AB, Siegel RL, Stein KD, Kramer JL, Alteri R, Robbins AS and Jemal A. Cancer treatment and survivorship statistics, 2014. CA. 2014; 64:252-271.

2. Siegel R, Ma J, Zou Z and Jemal A. Cancer statistics, 2014. CA. 2014; 64:9-29.

3. Cancer Genome Atlas Research N, Kandoth C, Schultz N, Cherniack AD, Akbani R, Liu Y, Shen H, Robertson AG, Pashtan I, Shen R, Benz CC, Yau C, Laird PW, Ding L, Zhang W, Mills GB, et al. Integrated genomic characterization of endometrial carcinoma. Nature. 2013; 497:67-73.

4. Dowdy SC. Improving oncologic outcomes for women with endometrial cancer: realigning our sights. Gynecologic oncology. 2014; 133:370-374.

5. Tyson JJ, Baumann WT, Chen C, Verdugo A, Tavassoly I, Wang Y, Weiner LM and Clarke R. Dynamic modelling of oestrogen signalling and cell fate in breast cancer cells. Nature reviews Cancer. 2011; 11:523-532.

6. Matsumoto M, Yamaguchi Y, Seino Y, Hatakeyama A, Takei H, Niikura H, Ito K, Suzuki T, Sasano H, Yaegashi $\mathrm{N}$ and Hayashi S. Estrogen signaling ability in human endometrial cancer through the cancer-stromal interaction. Endocrine-related cancer. 2008; 15:451-463.

7. Howell A, Cuzick J, Baum M, Buzdar A, Dowsett M, Forbes JF, Hoctin-Boes G, Houghton J, Locker GY and Tobias JS. Results of the ATAC (Arimidex, Tamoxifen, Alone or in Combination) trial after completion of 5 years' adjuvant treatment for breast cancer. Lancet. 2005; 365:6062.

8. Howell A. Pure oestrogen antagonists for the treatment of advanced breast cancer. Endocrine-related cancer. 2006; 13:689-706.

9. Giguere V, Yang N, Segui P and Evans RM. Identification of a new class of steroid hormone receptors. Nature. 1988; 
$331: 91-94$.

10. Stein RA and McDonnell DP. Estrogen-related receptor alpha as a therapeutic target in cancer. Endocrine-related cancer. 2006; 13 Suppl 1:S25-32.

11. Laudet V, Hanni C, Coll J, Catzeflis F and Stehelin D. Evolution of the nuclear receptor gene superfamily. The EMBO journal. 1992; 11:1003-1013.

12. Sladek R, Bader JA and Giguere V. The orphan nuclear receptor estrogen-related receptor alpha is a transcriptional regulator of the human medium-chain acyl coenzyme A dehydrogenase gene. Mol Cell Biol. 1997; 17:5400-5409.

13. Vanacker JM, Bonnelye E, Chopin-Delannoy S, Delmarre C, Cavailles V and Laudet V. Transcriptional activities of the orphan nuclear receptor ERR alpha (estrogen receptorrelated receptor-alpha). Molecular endocrinology. 1999; 13:764-773.

14. Bookout AL, Jeong Y, Downes M, Yu RT, Evans RM and Mangelsdorf DJ. Anatomical profiling of nuclear receptor expression reveals a hierarchical transcriptional network. Cell. 2006; 126:789-799.

15. Ichida $\mathrm{M}$, Nemoto $\mathrm{S}$ and Finkel $\mathrm{T}$. Identification of a specific molecular repressor of the peroxisome proliferatoractivated receptor gamma Coactivator-1 alpha (PGC1alpha). The Journal of biological chemistry. 2002; 277:50991-50995.

16. Suzuki T, Miki Y, Moriya $T$, Shimada N, Ishida $T$, Hirakawa H, Ohuchi N and Sasano H. Estrogen-related receptor alpha in human breast carcinoma as a potent prognostic factor. Cancer research. 2004; 64:4670-4676.

17. Fujimura T, Takahashi S, Urano T, Kumagai J, Ogushi T, Horie-Inoue K, Ouchi Y, Kitamura T, Muramatsu M and Inoue $\mathrm{S}$. Increased expression of estrogen-related receptor alpha (ERRalpha) is a negative prognostic predictor in human prostate cancer. International journal of cancer. 2007; 120:2325-2330.

18. Cavallini A, Notarnicola M, Giannini R, Montemurro S, Lorusso D, Visconti A, Minervini F and Caruso MG. Oestrogen receptor-related receptor alpha (ERRalpha) and oestrogen receptors (ERalpha and ERbeta) exhibit different gene expression in human colorectal tumour progression. European journal of cancer. 2005; 41:1487-1494.

19. Watanabe A, Kinoshita Y, Hosokawa K, Mori T, Yamaguchi T and Honjo H. Function of estrogen-related receptor alpha in human endometrial cancer. The Journal of clinical endocrinology and metabolism. 2006; 91:15731577.

20. Sun P, Sehouli J, Denkert C, Mustea A, Konsgen D, Koch I, Wei L and Lichtenegger W. Expression of estrogen receptor-related receptors, a subfamily of orphan nuclear receptors, as new tumor biomarkers in ovarian cancer cells. Journal of molecular medicine (Berlin, Germany). 2005; 83:457-467.

21. Wu J, Brandt S and Hyder SM. Ligand- and cell-specific effects of signal transduction pathway inhibitors on progestin-induced vascular endothelial growth factor levels in human breast cancer cells. Molecular endocrinology. 2005; 19:312-326.

22. Ma J, Sawai H, Ochi N, Matsuo Y, Xu D, Yasuda A, Takahashi H, Wakasugi $\mathrm{T}$ and Takeyama H. PTEN regulates angiogenesis through $\mathrm{PI} 3 \mathrm{~K} / \mathrm{Akt} / \mathrm{VEGF}$ signaling pathway in human pancreatic cancer cells. Molecular and cellular biochemistry. 2009; 331:161-171.

23. Fleming GF. Systemic chemotherapy for uterine carcinoma: metastatic and adjuvant. Journal of clinical oncology. 2007; 25:2983-2990.

24. Fujimoto J and Sato E. Clinical implication of estrogenrelated receptor (ERR) expression in uterine endometrial cancers. The Journal of steroid biochemistry and molecular biology. 2009; 116:71-75.

25. Gao M, Sun P, Wang J, Zhao D and Wei L. Expression of estrogen receptor-related receptor isoforms and clinical significance in endometrial adenocarcinoma. International journal of gynecological cancer. 2006; 16:827-833.

26. Dufour CR, Wilson BJ, Huss JM, Kelly DP, Alaynick WA, Downes M, Evans RM, Blanchette M and Giguere V. Genome-wide orchestration of cardiac functions by the orphan nuclear receptors ERRalpha and gamma. Cell metabolism. 2007; 5:345-356.

27. Hanahan D and Weinberg RA. Hallmarks of cancer: the next generation. Cell. 2011; 144:646-674.

28. Wang J, Taylor A, Showeil R, Trivedi P, Horimoto Y, Bagwan I, Ewington L, Lam EW and El-Bahrawy MA. Expression profiling and significance of VEGF-A, VEGFR2, VEGFR3 and related proteins in endometrial carcinoma. Cytokine. 2014; 68:94-100.

29. Sivridis E, Giatromanolaki A, Anastasiadis P, Georgiou L, Gatter KC, Harris AL, Bicknell R and Koukourakis MI. Angiogenic co-operation of VEGF and stromal cell TP in endometrial carcinomas. The Journal of pathology. 2002; 196:416-422.

30. Arany Z, Foo SY, Ma Y, Ruas JL, Bommi-Reddy A, Girnun G, Cooper M, Laznik D, Chinsomboon J, Rangwala SM, Baek KH, Rosenzweig A and Spiegelman BM. HIFindependent regulation of VEGF and angiogenesis by the transcriptional coactivator PGC-1alpha. Nature. 2008; 451:1008-1012.

31. Stein RA, Gaillard S and McDonnell DP. Estrogenrelated receptor alpha induces the expression of vascular endothelial growth factor in breast cancer cells. The Journal of steroid biochemistry and molecular biology. 2009; 114:106-112.

32. Ao A, Wang H, Kamarajugadda S and Lu J. Involvement of estrogen-related receptors in transcriptional response to hypoxia and growth of solid tumors. Proceedings of the National Academy of Sciences of the United States of America. 2008; 105:7821-7826.

33. Mori T, Sawada M, Kuroboshi H, Tatsumi H, Katsuyama $\mathrm{M}$, Iwasaku K and Kitawaki J. Estrogen-related receptor 
alpha expression and function are associated with vascular endothelial growth factor in human cervical cancer. International journal of gynecological cancer. 2011; 21:609615.

34. Huh JI, Calvo A, Stafford J, Cheung M, Kumar R, Philp D, Kleinman HK and Green JE. Inhibition of VEGF receptors significantly impairs mammary cancer growth in C3(1)/ Tag transgenic mice through antiangiogenic and nonantiangiogenic mechanisms. Oncogene. 2005; 24:790-800.

35. Stein RA, Chang CY, Kazmin DA, Way J, Schroeder T, Wergin M, Dewhirst MW and McDonnell DP. Estrogenrelated receptor alpha is critical for the growth of estrogen receptor-negative breast cancer. Cancer research. 2008; 68:8805-8812.

36. Bianco S, Lanvin O, Tribollet V, Macari C, North S and Vanacker JM. Modulating estrogen receptor-related receptor-alpha activity inhibits cell proliferation. The Journal of biological chemistry. 2009; 284:23286-23292.

37. Blagosklonny MV, Giannakakou P, el-Deiry WS, Kingston DG, Higgs PI, Neckers L and Fojo T. Raf-1/bcl-2 phosphorylation: a step from microtubule damage to cell death. Cancer research. 1997; 57:130-135.

38. Wang J, Beauchemin M and Bertrand R. Phospho-Bcl$\mathrm{xL}($ Ser62) influences spindle assembly and chromosome segregation during mitosis. Cell cycle (Georgetown, Tex). 2014; 13:1313-1326.

39. Mita AC, Mita MM, Nawrocki ST and Giles FJ. Survivin: key regulator of mitosis and apoptosis and novel target for cancer therapeutics. Clinical cancer research. 2008; 14:5000-5005.
40. Li F, Ambrosini G, Chu EY, Plescia J, Tognin S, Marchisio PC and Altieri DC. Control of apoptosis and mitotic spindle checkpoint by survivin. Nature. 1998; 396:580-584.

41. Li Z, Min W and Gou J. Knockdown of cyclophilin A reverses paclitaxel resistance in human endometrial cancer cells via suppression of MAPK kinase pathways. Cancer chemotherapy and pharmacology. 2013; 72:1001-1011.

42. Deblois G, Hall JA, Perry MC, Laganiere J, Ghahremani M, Park M, Hallett M and Giguere V. Genome-wide identification of direct target genes implicates estrogenrelated receptor alpha as a determinant of breast cancer heterogeneity. Cancer research. 2009; 69:6149-6157.

43. Yamamoto T, Mori T, Sawada M, Matsushima H, Ito F, Akiyama $\mathrm{M}$ and Kitawaki J. Loss of AF-6/afadin induces cell invasion, suppresses the formation of glandular structures and might be a predictive marker of resistance to chemotherapy in endometrial cancer. BMC cancer. 2015; 15:275.

44. Morgan DA, Refalo NA and Cheung KL. Strength of ERpositivity in relation to survival in ER-positive breast cancer treated by adjuvant tamoxifen as sole systemic therapy. Breast (Edinburgh, Scotland). 2011; 20:215-219.

45. Ushida H, Chano T, Minami K, Kita H, Kawakami T, Okabe H, Okada Y and Okamoto K. Therapeutic potential of SOX2 inhibition for embryonal carcinoma. The Journal of urology. 2012; 187:1876-1881. 